\title{
Efficacy and safety of intravenous amiodarone in recent-onset atrial fibrillation: experience in patients admitted to a general internal medicine department
}

\author{
Yitshak Kreiss, Yechezkel Sidi, Hanan Gur
}

\begin{abstract}
Summary
We examined the efficacy and safety of intravenous amiodarone in 20 unselected patients with recent-onset atrial fibrillation who were admitted to a general internal medicine department during a 6-month period. The treatment protocol included a loading dose of $1200 \mathrm{mg}$ intravenous amiodarone in 24 hours, after which amiodarone treatment was continued orally. Eleven of the 20 patients $(55 \%)$ converted to sinus rhythm within 48 hours of intravenous amiodarone treatment and were discharged in sinus rhythm, while $9 / 20(45 \%)$ patients failed to convert during hospitalisation. Six patients $(30 \%)$ failed to convert to sinus rhythm even after one further month of oral treatment. There was one death and a high frequency $(25 \%)$ of thrombophlebitis during hospitalisation. The inhospital non-convertors had a significantly lower ejection fraction and initial low ventricular response rate than the convertors. In conclusion, the acute conversion rate by intravenous amiodarone was at best modest. It is suggested that intravenous amiodarone is probably more effective in patients with rapid recent-onset atrial fibrillation and good left ventricular function.
\end{abstract}

Keywords: amiodarone; atrial fibrillation

Recent-onset atrial fibrillation (ROAF) is a common finding in patients admitted to general internal medicine departments. The optimal way to safely convert this arrhythmia to sinus rhythm has not been elucidated and has been the subject of much debate. The conventional use of class $1 \mathrm{~A}$ anti-arrhythmic drugs, such as quinidine or procaineamide, has recently been relinquished, due to potentially dangerous pro-arrhythmogenicity. ${ }^{1}$ Moreover, even type 1C anti-arrhythmic drugs, such as propafenone and flecainide, which are highly effective in converting ROAF to sinus rhythm, ${ }^{23}$ carry the pro-arrhythmic risk of transformation of atrial fibrillation to flutter with 1:1 atrioventricular conduction and haemodynamic compromise. ${ }^{45}$
Intravenous infusion of amiodarone has been shown to be useful, though with variable efficacy, for control of ventricular rate and conversion of ROAF. ${ }^{6-14}$ However, adverse reactions such as phlebitis, bradycardia, AV block, hypotension, ${ }^{1516}$ aggravation of heart failure, torsade de pointes ${ }^{17}{ }^{18}$ and death, ${ }^{6}$ have been reported with short-term administration of amiodarone. Subsequently, it has been suggested that intravenous amiodarone should be used cautiously, as it may have lethal complications. ${ }^{6}$ Therefore, most studies of the feasibility of acute amiodarone loading in ROAF, have been carried out in coronary care units or in highly selected patients. ${ }^{6}{ }^{19}$ Moreover, previous studies have focused on the acute (24-hour) effect of amiodarone and data on longer periods of observation in ROAF patients treated with intravenous amiodarone are incomplete.

The aims of the present study were to examine prospectively the efficacy and safety of intravenous amiodarone treatment in an unselected population of patients with ROAF who had been admitted to a general internal medicine department. The effect of amiodarone was assessed both short-term (up to 3 days in hospital) and a month later.

\section{Patients and methods}

We prospectively studied all patients with ROAF ( $<48 \mathrm{~h}$ ) admitted to the Department of Medicine C (a 38-bed general internal medical department) during a 6-month period. Onset of arrhythmia was documented by electrocardiograph (ECG) or by an abrupt onset of palpitations with subsequent evidence of atrial fibrillation on ECG.

Patients were excluded for any of the following reasons: pulmonary oedema, hypotension (systolic blood pressure $<90 \mathrm{mmHg}$ ), mean ventricular rate during atrial fibrillation less than 70 beats/min, previous or current ECG evidence of ventricular pre-excitation, previous evidence of second- or third-degree atrioventricular block, hypokalaemia (serum potassium $<3.5 \mathrm{mmol} / \mathrm{l})$, severe hypoxia $\left(\mathrm{O}_{2}\right.$ sat $\left.<90 \%\right)$, acidosis $(\mathrm{pH}<7.35)$, significant liver disease or hepatitis, renal failure (serum creatinine $>3$ $\mathrm{mg} / \mathrm{dl}$ ), known thyroid dysfunction, patients already taking amiodarone and patients with an atrial thrombus on echocardiography. 
Table 1 Patient characteristics

\begin{tabular}{|c|c|c|c|}
\hline Characteristic & $\begin{array}{l}\text { All patients } \\
(n=20)\end{array}$ & $\begin{array}{l}\text { Group } I^{*} \\
(n=11)\end{array}$ & $\begin{array}{l}\text { Group } \\
(n=9)\end{array} I^{\star \star}$ \\
\hline $\begin{array}{l}\text { Mean age } \pm \text { SD (years) } \\
\text { Males } \\
\text { Females }\end{array}$ & $\begin{array}{l}71 \pm 11 \\
11(55 \%) \\
9(45 \%)\end{array}$ & $\begin{array}{l}72 \pm 10 \\
6(54 \%) \\
5(45 \%)\end{array}$ & $\begin{array}{l}70 \pm 10 \\
5(55 \%) \\
4(45 \%)\end{array}$ \\
\hline $\begin{array}{l}\text { Heart disease status: } \\
\text { No structural heart disease } \\
\text { Coronary heart disease } \\
\text { Valvular heart disease: } \\
\text { Mitral regurgitation } \\
\text { Aortic regurgitation } \\
\text { Aortic stenosis } \\
\text { Mitral stenosis } \\
\text { Cardiomyopathy/hypertension }\end{array}$ & $\begin{array}{l}7(35 \%) \\
9(45 \%) \\
10(50 \%) \\
7(35 \%) \\
2(10 \%) \\
1(5 \%) \\
1(10 \%) \\
\text { none }\end{array}$ & $\begin{array}{l}4(36 \%) \\
4(36 \%) \\
7(64 \%) \\
6(54 \%) \\
1(9 \%) \\
\text { none } \\
1(9 \%) \\
\text { none }\end{array}$ & $\begin{array}{l}3(33 \%) \\
5(55 \%) \\
3(33 \%) \\
1(11 \%) \\
1(11 \%) \\
1(11 \%) \\
\text { none } \\
\text { none }\end{array}$ \\
\hline $\begin{array}{l}\text { Echocardiographic data }{ }^{\star \star \star} \text { : } \\
\text { Ejection fraction }(\%) \text { : } \\
\text { range } \\
\text { mean } \pm \mathrm{SD}^{\star \star \star \star} \\
\text { median }\end{array}$ & $\begin{array}{l}30-60 \\
49 \pm 17 \\
50\end{array}$ & $\begin{array}{l}35-60 \\
53 \pm 8 \\
55\end{array}$ & $\begin{array}{l}30-60 \\
44 \pm 10 \\
45\end{array}$ \\
\hline $\begin{array}{l}\text { Left atrial diameter }(\mathrm{mm}) \text { : } \\
\text { mean } \pm \text { SD } \\
\text { median } \pm \text { SD } \\
\text { Left atrial diameter }>40 \mathrm{~mm}\end{array}$ & $\begin{array}{l}42 \pm 6 \\
41 \\
11 / 19(58 \%)\end{array}$ & $\begin{array}{l}41 \pm 2 \\
41 \\
6(54 \%)\end{array}$ & $\begin{array}{l}43 \pm 8 \\
43 \\
5(55 \%)\end{array}$ \\
\hline $\begin{array}{l}\text { Heart failure: } \\
\text { NYHA Class I } \\
\text { NYHA Class II }\end{array}$ & $\begin{array}{l}1(5 \%) \\
4(20 \%)\end{array}$ & $\begin{array}{l}1(9 \%) \\
2(18 \%)\end{array}$ & $\begin{array}{l}\text { none } \\
2(22 \%)\end{array}$ \\
\hline $\begin{array}{l}\text { Associated diseases: } \\
\text { Hypertension } \\
\text { Diabetes mellitus } \\
\text { Previous cerebral stroke } \\
\text { Chronic obstructive pulmonary disease }\end{array}$ & $\begin{array}{l}12(60 \%) \\
7(35 \%) \\
3(15 \%) \\
1(5 \%)\end{array}$ & $\begin{array}{l}6(54 \%) \\
2(18 \%) \\
1(9 \%) \\
-\end{array}$ & $\begin{array}{l}6(67 \%) \\
5(66 \%) \\
2(22 \%) \\
1(11 \%)\end{array}$ \\
\hline
\end{tabular}

Eligible patients had continuous monitoring of their ECG. In addition, a 12-lead ECG and blood pressure measurements were performed initially, after 1, 8 and 24 hours, and then every 24 hours for 3 consecutive days. The blood pressure was measured thrice daily thereafter. When patients converted to sinus rhythm, a 12-lead ECG was done immediately. Sustained conversion was defined as stable sinus rhythm that lasted for at least 24 hours and was also evident on discharge. All patients were examined twice daily by the treating physicians. Further data obtained on each patient included clinical history, results of physical examination, chest X-rays and trans-thoracic echocardiography.

The treatment protocol included a loading of $300 \mathrm{mg}$ intravenous amiodarone infusion via a peripheral line (Venflon 18G, $45 \mathrm{~mm}$, Omehda $\mathrm{AB}$, Helsingborg, Sweden) at a rate of 10 $\mathrm{mg} / \mathrm{min}$, followed by $900 \mathrm{mg}$ at a rate of 37.5 $\mathrm{mg} / \mathrm{h}$. After this $24-\mathrm{h}$ intravenous loading regimen, loading was continued orally with 1200 $\mathrm{mg}$ amiodarone per day for 3 days, followed by $800 \mathrm{mg}$ for the next 3 days, then $400 \mathrm{mg}$ daily for 3 days. Subsequent maintenance dose was $200 \mathrm{mg} /$ day.

After 3 days in hospital all patients were discharged on oral amiodarone as scheduled above, and were subsequently examined after one month to assess whether they had converted to (those who failed the in-hospital short-term amiodarone treatment) or maintained sinus rhythm (those who had been discharged in sinus rhythm). All patients received oral anticoagulant therapy to keep the INR between 2.5-3.0.
STATISTICAL ANALYSIS

Quantitative data were expressed as means \pm SD. For the comparison of continuous variables, two-tailed Student $t$-test was used. Comparisons of proportions were done by Chi-square or Fisher's exact test. p-Values less than 0.05 were considered to indicate statistical significance.

\section{Results}

PATIENT CHARACTERISTICS

During the study period, 188 patients with atrial fibrillation were admitted to our department. The majority (162 patients, $86 \%$ ) were patients with chronic atrial fibrillation, atrial fibrillation of unknown age, or of more than 48 hours duration. Twenty-six patients presented with ROAF, 20 of whom $(77 \%)$ were eligible for intravenous amiodarone. Six patients $(23 \%)$ were excluded for one or more of the following reasons: two patients had already been on amiodarone treatment, and one patient each because of end-stage-renal failure, severe hypotension, and large left atrial thrombus revealed in initial echocardiogram; one patient refused therapy. Four of these six patients were discharged with sinus rhythm; they were treated with digoxin (one patient), propranolol (one patient), verapamil (two out of four patients).

The demographic, clinical and echocardiographic characteristics of the patients included in the study are summarised in table 1.

OUTCOME OF AMIODARONE TREATMENT

Eleven of the 20 patients (55\%) converted to sinus rhythm within 48 hours of intravenous amiodarone treatment. The mean duration of atrial fibrillation from treatment to conversion was $11.8 \pm 13.7 \mathrm{~h}$, median $8 \mathrm{~h}$, range $1-48 \mathrm{~h}$. All of these patients, designated group I, were discharged in sinus rhythm, and continued on oral amiodarone according to the described protocol. One month later they were examined and all were in sinus rhythm.

Nine of the 20 patients (45\%) failed to convert in hospital (group II, 'non-convertors'), and continued oral amiodarone for one month along with oral anticoagulation. Three of these patients (15\%, group IIa), successfully and uneventfully converted to sinus rhythm during the first month. However, six (30\%, group IIb) failed to convert to sinus rhythm even after one month of treatment.

A comparison of the characteristics of groups I and II is shown in table 1 . As can be seen, the groups were similar in all the parameters examined, except for a reduced mean ejection fraction of group II (non-convertors), compared to group I (in-hospital convertors; $\mathrm{p}=0.02)$. The ejection fraction as well as other clinical characteristics were similar in groups IIa and IIb (data not shown).

EFFECTS ON THE VENTRICULAR RESPONSE RATE A proposed advantage of intravenous amiodarone treatment is its ability to slow the ventricular response rate, even without converting to sinus rhythm. As shown in table 2, the mean 
Table 2 Amiodarone effects on ventricular response rates. The values presented in the table are the mean $\pm \mathrm{SD}$ ventricular response rate per minute. Group I are in-hospital convertors, group II are in-hospital non-convertors

\begin{tabular}{llllll}
\hline & \multicolumn{5}{l}{ Time (hours } \\
\cline { 2 - 6 } & 0 & 1 & 8 & 24 & $p_{\text {-Value }}^{\star \star}$ \\
\hline All patients & $113 \pm 30$ & $100 \pm 24$ & $82 \pm 19$ & $78 \pm 17$ & $0.07 ; 0.001$ \\
Group I & $130 \pm 29$ & $108 \pm 27$ & $83 \pm 21$ & $79 \pm 22$ & $0.035 ; 0.001$ \\
Group II & $92 \pm 17$ & $91 \pm 17$ & $88 \pm 18$ & $77 \pm 10$ & $0.42 ; 0.4$ \\
p-Value & 0.002 & 0.05 & 0.24 & 0.45 & \\
\hline
\end{tabular}

${ }^{\star}$ The p-value of each column refers to the comparison of groups I and II. ${ }^{\star \star}$ The p-values of each row refer to the comparison of initial rate with the rates after 1 and 8 hours, respectively. The difference between 8 and 24 hours was not significant for the two groups.

initial ventricular rate of all patients examined was $113 \pm 30$ beats/min. After the first hour of intravenous amiodarone the rate decreased to $100 \pm 24$ beats $/ \mathrm{min}(\mathrm{p}=0.07)$, and after 8 hours the rate dropped to $82 \pm 19$ beats/min $(\mathrm{p}=0.001)$ without further significant change after 24 hours $(78 \pm 17$ beats/min, $\mathrm{p}=0.12$ for comparison of 8 and 24 hours). The same pattern was observed in group I. In contrast, the nine patients in group II had an initial ventricular response of $92 \pm 17$ beats/min which was not affected by intravenous amiodarone treatment. Moreover, the initial ventricular rate differed significantly between in-hospital responders and non-responders (mean 130 29 beats/min, median 140 beats/min vs mean $92 \pm 13$ beats $/ \mathrm{min}$, median of 90 beats $/ \mathrm{min}$, respectively, $\mathrm{p}=0.002$ ).

\section{ADVERSE EFFECTS}

One patient died during hospitalisation. This was a 55-year-old man who had mitral regurgitation with poor left ventricular systolic function (ejection fraction $30 \%$ ), associated with pulmonary hypertension $(60 \mathrm{mmHg})$ and tricuspid regurgitation. He died on the 5th in-hospital day (4 days after completion of intravenous amiodarone loading, while he was receiving oral amiodarone according to the protocol, without converting to sinus rhythm) from ventricular fibrillation.

The most common side-effect was thrombophlebitis observed in five (25\%) patients. The phlebitis was superficial, mild and reversible. One patient had transient hypotension $(90 / 55 \mathrm{mmHg})$ during the second day of loading. No additional side-effects (such as prolongation of the QT interval, atrio-ventricular block or abnormal liver function tests) were observed, even after one month of treatment.

\section{Discussion}

Previous studies on the ability of intravenously administered amiodarone to revert ROAF focused on more selected patients in coronary care units ${ }^{2021}$ or after cardiac surgery. ${ }^{22}$ The department of medicine in our institution admits unselected patients from the emergency room. Hence, compared to previous reports, ${ }^{6}{ }^{12} 1320$ the patients in the present study were older, with a mean age of $71 \pm 11$ years. Thus, the present report is the first prospective study on the efficacy and safety of intravenous amiodarone administered in a general internal medicine set-up.

The data of the present study show that only $11 / 20$ patients $(55 \%)$ converted to sinus rhythm within 48 hours of amiodarone loading. Continued oral amiodarone loading for 1 month resulted in three additional patients who converted and remained in sinus rhythm. Hence, $30 \%$ of the study patients failed to convert to sinus rhythm even after extended loading of amiodarone. This conversion rate is disappointing, especially considering that four of six patients who were excluded from the study and had not received intravenous amiodarone, were in sinus rhythm at discharge.

One patient died, although the death occurred 4 days after completion of the intravenous loading and was probably related to his advanced cardiac condition. The treatment was associated with some side-effects, especially thrombophlebitis which was observed in $25 \%$ of the patients. It is possible, however, that the high frequency of thrombophlebitis in the present study resulted from the use of a short peripheral intravenous line, along with relatively high concentrations of loading solution $(1.5-3 \mathrm{mg} / \mathrm{ml})$. Following the study period, we have used a lower loading concentration (1 $\mathrm{mg} / \mathrm{ml}$ ) and the rate of phlebitis has declined substantially.

The relatively modest efficacy of intravenous amiodarone in conversion of ROAF to sinus rhythm in the present report is in accordance with the results of a recent study ${ }^{13}$ which compared intravenous amiodarone and placebo (both groups received digoxin), showing a non-significant difference between amiodarone and control in conversion rates $(68 \%$ vs $60 \%$ after 24 hours). Similarly, Donovan et al detected no differences in conversion rates of ROAF between amiodarone (59\%) and placebo $(56 \%)$ after 8 hours of observation. ${ }^{23}$ In contrast, Hou et al have recently reported conversion rates as high as $92 \%$ for amiodarone compared to digoxin (71\%) within 24 hours. $^{6}$ However, the patients were admitted to a coronary care unit and received a tailored dosing regimen, which is not applicable to a general internal medicine department. Others have reported a lower conversion rate of $64 \%$ of patients treated in a coronary care unit. ${ }^{20}$

Comparable to the present report, and despite the large numbers of patients treated (142 consecutive patients), no significant adverse or pro-arrhythmic effects of amiodarone were observed. ${ }^{20}$ In contrast, thrombophlebitis was a common side-effect in our study, affecting $25 \%$ of the patients, a frequency higher than previously reported. ${ }^{6}{ }^{12} 13$

Analysis of the present data reveal two major characteristics of the patients who responded to the intravenous amiodarone loading. First, confirming a previous report, ${ }^{12}$ the mean ejection fraction of the responders (group I), was significantly higher than the nonresponders (group II). In contrast, left atrial diameter was comparable between the two groups, as found by Galve et al. ${ }^{13}$ Second, two patterns of amiodarone effect on the ventricular response rate were observed. In the 
responders (group I), amiodarone significantly decreased the heart rate, an effect noticed as early as one hour after loading. This rapid effect on heart rate has been observed previously ${ }^{1324}$ and is probably induced by prolongation of the A-H interval and atrioventricular junctional effective refractory period. ${ }^{25}{ }^{26}$ In contrast, the rate-time curve of the non-responders was flat. Moreover, the non-responders were characterised by a significant initial slow ventricular response. To the best of our knowledge, this distinctive feature has not been shown in previous reports. Since intravenous amiodarone inhibits inactivated sodium channels, especially those with shorter cycle lengths, ${ }^{27-30}$ it is possible that its antiarrhythmic action is greater during rapid tachyarrhythmia. ${ }^{14}$

1 Roden DM. Risks and benefits of antiarrhythmic therapy. $N$ Engl f Med 1994;331:785-91.

2 Boriani G, Biffi M, Capucci A, et al. Oral propafenone to convert recent-onset atrial fibrillation in patients with and without underlying heart disease. A randomized, controlled trial. Ann Intern Med 1997;126:621-5.

3 Capucci A, Boriani G, Rubino I, et al. A controlled study on oral propafenone versus digoxin plus quinidine in converting recent onset atrial fibrillation to sinus rhythm. Int f Cardiol 1994;43:305-15.

4 Marcus FI. The hazards of using type 1C antiarrhythmic Marcus FI. The hazards of using type 1C antiarrhythmic drugs for the treatment of
7 Cardiol 1990;66:366-7.

5 Feld GK, Chen PS, Nicod P, et al. Possible atrial proarrhythmic effects of class $1 \mathrm{C}$ antiarrhythmic drugs. $\mathrm{Am}$ f Cardiol 1990;66:378-83.

6 Hou ZY, Chang MS, Chen CY, et al. Acute treatment of recent-onset atrial fibrillation and flutter with a tailored dosing regimen of intravenous amiodarone. A randomized, digoxin-controlled study. Eur Heart $\mathcal{F}$ 1995;16:521-8.

7 Blandford RL, Crampton J, Kudlac H. Intravenou amiodarone in atrial fibrillation complicating myocardial infarction. BMF 1982;284:16-7.

8 Strasberg B, Arditti A, Scalorovski S, et al. Efficacy of intravenous amiodarone in the management of paroxysmal or new atrial fibrillation with fast ventricular response. Int $\mathcal{f}$ new atrial fibrillation $1985 ; 7: 47-55$.

9 Holt P, Crick JCP, Davies DW, et al. Intravenous amiodarone in the acute termination of supraventricular amiodarone in the acute termination
arrhythmia. Int $\mathcal{F}$ Cardiol 1985;8:67-76.

10 Noc M, Stajer D, Horvat M. Intravenous amiodarone versus verapamil for acute conversion of paroxysmal atrial fibrillaverapamil for acute conversion of paroxysmal atrial
tion to sinus rhythm. Am f Cardiol 1990;65:679-80.

11 McAllister HF, Luke RA, Whitlock RM, et al. Intravenous amiodarone bolus versus oral quinidine for atrial flutter and fibrillation after cardiac operation. F Thorac Cardiovasc Surg 1990;99:911-918

12 Vietti-Ramus G, Veglio F, Marchisio U, et al. Efficacy and safety of short intravenous amiodarone in supraventricular tachyarrhythmia. Int $\mathcal{F}$ Cardiol 1992;35:77-85.

13 Galve E, Rius T, Ballester R, et al. Intravenous amiodarone in the treatment of recent-onset atrial fibrillation: results of a randomized controlled study. F Am Coll Cardiol 1996;27: 1079-82.

14 Desai A, Chun S, Sung R. The role of intravenous amiodarone in the management of cardiac arrhythmias. Ann Intern Med 1997;127:294-303.

15 Clara F. Intravenous amiodarone in atrial fibrillation complicating myocardial infarction. BMF 1982;284:506-7. 16 Schwartz A, Shen E, Morady F, et al. Hemodynamic effects of intravenous amiodarone in patients with depressed left ventricular function and recurrent ventricular tachycardia. Am Heart f 1983;106:848-56.
The present study is too small to draw conclusions regarding mechanisms, and further studies are needed to confirm and examine the differential effect of amiodarone on atrial fibrillation with a slow vs rapid ventricular response.

In conclusion, intravenous amiodarone was feasible and relatively safe in a set-up of general internal medicine department. However, the acute conversion rate was disappointing. It is suggested that intravenous amiodarone is probably more effective in patients with rapid ROAF and good left ventricular function.

We would like to thank Prof Micha Eldar, Head of The Electrophysiological Service, The Heart Institute, Sheba Medical Center, Tel Hashomer, Israel, for reviewing the manuscript and for his valuable remarks.

17 Leroy G, Haiat R, Barthelemy M, et al. Torsade de pointes during loading with amiodarone. Eur Heart f 1987;8:541-3.

18 Brown MA, Smith WM, Lubbe WF, et al. Amiodaroneinduced torsades de pointes. Eur Heart 7 1986;7:234-9.

19 Chapman MJ, Moran JL, O'Fathartaigh MS, et al. Management of atrial tachyarrhythmia in the critically ill: a comparison of intravenous procaineamide and amiodarone. Intens Care Med 1993;19:58-2.

20 Cybulski J, Kulakowski P, Makowska E, et al. Intravenous amiodarone is safe and seems to be effective in termination of paroxysmal supraventricular tachyarrhythmias. Clin Cardiol 1996;19:563-6.

21 Kumar A. Intravenous amiodarone for therapy of atrial fibrillation and flutter in critically ill patients with severely depressed left ventricular function. South Med J 1996;89: $779-85$.

22 Hohnloser SH, Meinetz T, Dammbacher T, et al. Electrocardiographic and antiarrhythmic effects of intravenous amiodarone: results of a prospective, placebo-controlled study. Am Heart f 1991;121:89-95.

23 Donovan KD, Power BM, Hockings BEF, et al. Intravenous flecainide versus amiodarone for recent-onset atrial fibrillation. Am f Cardiol 1995;75:693-7.

24 Kerin NZ, Faitel K, Naini M. The efficacy of intravenous amiodarone for the conversion of chronic atrial fibrillation. Amiodarone vs quinidine for conversion of atrial fibrillation. Arch Int Med 1996;156:49-53.

25 Singh BN, Venkatesh N, Nademanee K, et al. The historical development, cellular electrophysiology, and pharmacology of amiodarone. Prog Cardiovasc Dis 1989;31:249-80.

26 Wellens HJ, Brugada P, Abdollah $\mathrm{H}$, et al. A comparison of the electrophysiologic effects of intravenous and oral amiodarone in the same patient. Circulation 1984;69:120-4.

27 Morady F, DiCarlo LA Jr, Krol RB, et al. Acute and chronic effects of amiodarone on ventricular refractoriness, intraventricular conduction and ventricular tachycardia induction. 7 Am Coll Cardiol 1986;7:148-56.

28 Yabek SM, Kato R, Singh BN. Effects of amiodarone and its metabolite desethylamiodarone, on the electrophysiologic properties of isolated cardiac muscle. $\mathcal{F}$ Cardiovasc Pharmacol 1986;8:197-207.

29 Mayuga RD, Singer DH. Effects of intravenous amiodarone on electrical dispersion in normal and ischaemic tissues and on arrhythmia inducibility: monophasic action potential studies. Cardiovasc Res 1992;20:571-9.

30 Mason JW, Hondeghem LM, Katzung BJ. Block of inactivated sodium channels and of depolarization-induced automaticity in guinea pig papillary muscle by amiodarone. Circulat Res 1984;55:277-87. 